\title{
The Crystal Structure of Sodium Sulphite
}

\section{A Refinement Allowing for the Effect of Crystal Twinning}

\author{
LARS OLOF LARSSON and PEDER KIERKEGAARD
}

Institute of Inorganic and Physical Chemistry, University of Stockholm, Stockholm, Sweden

\begin{abstract}
The crystal structure of sodium sulphite, $\mathrm{Na}_{2} \mathrm{SO}_{3}$, has been refined by least-squares techniques on the basis of three-dimensional X-ray film and diffractometer data. The effect of twinning, which seems to be always present in crystals of this material, has been allowed for. The investigation has confirmed the general features of the atomic arrangement reported in 1931 by Zachariasen and Buckley but the $\mathrm{S}-\mathrm{O}$ distance has come out as $1.504 \pm 3 \AA$, to be compared with the value $1.39 \AA$ given by the previous authors.
\end{abstract}

$\mathbf{R}$ ecent structural studies on various metal sulphites, viz. $\mathrm{Cu}_{2} \mathrm{SO}_{3} \cdot \mathrm{CuSO}_{3} \cdot 2 \mathrm{H}_{2} \mathrm{O},{ }^{1}$ $\mathrm{NH}_{4} \mathrm{CuSO}_{3},{ }^{2} \quad \mathrm{Ag}_{2} \mathrm{SO}_{3},{ }^{3} \quad \mathrm{NiSO}_{3} \cdot 6 \mathrm{H}_{2} \mathrm{O},{ }^{4}$ and $\left(\mathrm{NH}_{4}\right)_{2} \mathrm{SO}_{3} \cdot \mathrm{H}_{2} \mathrm{O},{ }^{5}$ have given consistent geometrical results for the anion. Thus, the $\mathrm{S}-\mathrm{O}$ edges of the trigonal or pseudotrigonal $\mathrm{SO}_{3}{ }^{2-}$ pyramid fall within the range $1.50-1.53 \AA$ and the height of the $\mathrm{S}$ atom above the plane of the $\mathrm{O}$ atoms varies between $0.56 \AA$ and $0.64 \AA$. The $\mathrm{S}-\mathrm{O}$ distance of $1.54 \AA$, which has been theoretically derived is in good agreement with the distances observed. It is natural for the $\mathrm{S}-\mathrm{O}$ distances to be somewhat longer in the $\mathrm{SO}_{3}{ }^{2-}$ ion than in the tetrahedral $\mathrm{SO}_{4}{ }^{2-}$ anion $(1.48 \AA)$. The discrepancy between these data and the $\mathrm{S}-\mathrm{O}$ distance of $1.39 \AA$ in sodium sulphite reported by Zachariasen and Buckley ${ }^{6}$ is considerable. It was therefore thought worthwhile to undertake a structural refinement of this substance.

\section{PREPARATION AND CHARACTERIZATION OF THE MATERIAL}

Preparation of the crystals. The sample of $\mathrm{Na}_{2} \mathrm{SO}_{3}$ used in this investigation was synthesized by bubbling of $\mathrm{SO}_{2}$ through a carbonate-free $10 \mathrm{M}$ solution of sodium hydroxide. The white crystal mass thus obtained was recrystallized and after washing and drying transparent, hexagonal prisms were obtained. In order to avoid oxidation all operations were performed in a nitrogen atmosphere.

Infrared absorption spectrum. The infrared spectrum of a sample of $\mathrm{Na}_{2} \mathrm{SO}_{3}$ was recorded with a double beam Perkin-Elmer 21 spectrometer using the $\mathrm{KBr}$ technique and the usual precautions were applied to avoid contamination with water. Three maxima

Acta Chem. Scand. 23 (1969) No. 7 
of absorption were observed at 495,628 , and $970 \mathrm{~cm}^{-1}$, which frequencies are in good agreement with the values 493,626 , and $972 \mathrm{~cm}^{-1}$ reported in the literature. ${ }^{7}$

$X$-Ray powder diffraction data. The powder pattern of a sample was found to be in accordance with the data given by Swanson and Fayat. ${ }^{8}$ Values for the cell dimensions were calculated from a photograph taken with strictly monochromatized $\mathrm{Cu} K \alpha_{1}$ radiation $(\lambda=1.54050 \AA)$ in a Guinier-Hägg type focusing camera. Potassium chloride $(a=6.29228 \AA)^{8}$ was used as an internal standard. The dimensions of the hexagonal unit cell (see Table 1 ) at $25^{\circ} \mathrm{C}$ are:

$$
a=5.4587 \pm 5 \AA,(5.462 \AA),{ }^{8} c=6.1792 \pm 23 \AA,(6.176 \AA) .{ }^{8}
$$

Table 1. X-Ray powder data of $\mathrm{Na}_{2} \mathrm{SO}_{3} . \mathrm{Cu} K \alpha_{1}$ radiation. $\lambda\left(\mathrm{Cu} K \alpha_{1}\right)=1.54050 \AA$.

\begin{tabular}{|c|c|c|c|c|c|}
\hline$h k l$ & $\begin{array}{c}\sin ^{2} \theta \\
\text { obs }\end{array}$ & $\begin{array}{c}\sin ^{2} \theta \\
\text { calc }\end{array}$ & $d_{\text {obs }} \AA$ & $d_{\text {calc }} \AA$ & $I_{\mathrm{obs}}$ \\
\hline 100 & 0.02678 & 0.02654 & 4.70680 & 4.72736 & vvw \\
\hline 101 & 0.04214 & 0.04208 & 3.75218 & 3.75460 & $\mathrm{~m}$ \\
\hline 110 & 0.07972 & 0.07964 & 2.72802 & 2.72934 & $\mathrm{~m}$ \\
\hline 102 & 0.08886 & 0.08869 & 2.58391 & 2.58625 & $m-$ \\
\hline 111 & 0.09538 & 0.09518 & 2.49403 & 2.49664 & $\mathrm{~m}$ \\
\hline 200 & 0.10608 & 0.10619 & 2.36491 & 2.36368 & $w$ \\
\hline 201 & 0.12170 & 0.12172 & 2.20793 & 2.20767 & $w$ \\
\hline 202 & 0.16828 & 0.16834 & 1.87765 & 1.87730 & $\mathrm{~m}$ \\
\hline 210 & 0.18586 & 0.18583 & 1.78664 & 1.78677 & $w$ \\
\hline 212 & 0.24783 & 0.24798 & 1.54720 & 1.54674 & $\mathrm{~m} \mathrm{~d}$ \\
\hline 220 & 0.31861 & 0.31857 & 1.36458 & 1.36467 & $w$ \\
\hline 312 & 0.40726 & 0.40727 & 1.20695 & 1.20695 & $\mathrm{~m} \mathrm{~d}$ \\
\hline
\end{tabular}

\section{REFINEMENT OF THE CRYSTAL STRUCTURE}

From previous investigators it was known that crystals of $\mathrm{Na}_{2} \mathrm{SO}_{3}$ have a very strong tendency to be twinned. In fact, Zachariasen and Buckley ${ }^{6}$ had to base the structure determination on X-ray intensities diffracted by a twin and Batelle and Trueblood ${ }^{5}$ report unsuccessful efforts to get single crystals of sodium sulphite. Therefore, this investigation was started with the intention to find a crystal with a negligible twin effect or a crystal for which a correction for the twin contribution to the X-ray intensities could be made.

From rotation and Weissenberg photographs $(0 k l-2 k l)$ of several crystals, taken with $\mathrm{Cu} K$ radiation, it was concluded that the experimental observations were in accordance with the symmetry and space group, viz. No. 147 $\mathrm{P} \overline{3}$, given by Zachariasen and Buckley. ${ }^{6}$ Since the crystals studied could not be tested microscopically for the presence of twinning three-dimensional X-ray data were collected from a number of crystals. Comparison of $0 k l$ photographs taken at the beginning and at the end of every series of exposures of a crystal served to check that no decomposition of the material had affected the X-ray data.

The reflections were recorded with the multiple-film technique and the relative intensities were estimated visually by comparison with an intensity scale obtained from one reflection photographed with different exposure times. 
Least-squares refinements were then performed on the basis of the sets of data, obtained from the different crystals, after corrections for absorption and Lorentz-polarization effects and with the positional parameters reported by Zachariasen and Buckley ${ }^{6}$ as starting coordinates. The results of the refinements showed significant differences between the parameters obtained and the final $R$ values lay within the range $0.12-0.16$. Subsequent calculations of the $\mathrm{S}-\mathrm{O}$ distance gave values $\leq 1.45 \AA$. From the variations in the results it was obvious that the intensity material did not represent single crystal data.

The high accuracy $\mathrm{X}$-ray data necessary for the correction of the intensities for the effect of twinning from a well shaped prismatic crystal with dimensions $0.061 \mathrm{~mm}$ (in the direction of the $a$ axis) $\times 0.061 \mathrm{~mm}(b) \times 0.027 \mathrm{~mm}(c)$, were collected by means of a manual GE diffractometer using $\mathrm{Cu} K \alpha$ radiation. After corrections for absorption and Lorentz-polarisation effects a full-matrix least-squares refinement of the structural parameters was performed on the assumption that single crystal data had been collected. The refinement was considered as complete when the parameter shifts were less than one per cent of the standard deviations, at which stage the discrepancy index, $R$, was down to 0.154 . The $\mathrm{S}-\mathrm{O}$ distance calculated on the basis of the coordinates thus obtained was $1.48 \AA$. When the calculated structure factors after the last cycle were compared with the observed ones considerable differences were found for several pairs, $F_{h k l}$ and $F_{h k i}$, of reflections (cf. Table 2). These

Table 2. Comparison between observed and calculated structure factors for pairs of reflections and the calculated twin factor $\alpha$.

\begin{tabular}{|c|c|c|c|}
\hline$h k l$ & $F_{\text {obs }}$ & $F_{\text {calc }}$ & $\alpha$ \\
\hline$\frac{\overline{3}}{3} 5 \frac{2}{5}$ & $\begin{array}{l}16.79 \\
40.43\end{array}$ & $\begin{array}{r}3.60 \\
48.69\end{array}$ & $0.11_{3}$ \\
\hline 142 & 23.06 & 11.03 & $0.10 \mathrm{~g}$ \\
\hline$\overline{1} 4 \overline{2}$ & 59.09 & 61.46 & \\
\hline$\overline{4} 42$ & 19.02 & 5.03 & $0.11_{3}$ \\
\hline$\overline{4} 4 \overline{2}$ & 52.54 & 54.55 & \\
\hline 022 & 34.49 & 5.84 & $0.10_{2}$ \\
\hline $02 \overline{2}$ & 99.01 & 106.44 & \\
\hline$\overline{3} 22$ & 25.64 & 0.23 & $0.11_{0}$ \\
\hline$\overline{3} 2 \overline{2}$ & 73.57 & 77.30 & \\
\hline 32 & 15.29 & 5.30 & $0.11_{3}$ \\
\hline $53 \overline{2}$ & 43.70 & 42.38 & \\
\hline 112 & 32.43 & 2.60 & $0.10_{3}$ \\
\hline $1 \overline{2}$ & 89.60 & 100.78 & \\
\hline 4 & 19.79 & 3.34 & $0.10_{g}$ \\
\hline $61 \overline{4}$ & 58.50 & 58.90 & \\
\hline
\end{tabular}

differences could be explained assuming the crystal investigated to be twinned along the $c$-axis with two crystal individuals having opposite $c$ directions, i.e. the type of twin formation observed by Zachariasen and Buckley. ${ }^{6}$ By means of such pair of reflections, $F_{h k l}$ and $F_{h k l}$, a twin factor, $\alpha$, was calculated using the relation: 


$$
\left(F_{\text {obs }(h k l)}\right)^{2}-\left(F_{\text {calc }(h k l)}\right)^{2}=\alpha\left(F_{\text {calc }(h k i)}\right)^{2}
$$

The $\alpha$-values obtained are listed in Table 2 . Seven new sets of data, $F^{\prime}$ obs, were calculated with our IBM 1800 computer and using $\alpha=0.09,0.10,0.11$, $0.12,0.13,0.14$ and 0.15 , and the formula

$$
F^{\prime} \text { obs }(h k l)=\left[\left(F_{\text {obs }(h k l)}\right)^{2}-\alpha\left(F_{\text {obs }(h k i)}\right)^{2}\right]^{\frac{1}{2}}
$$

and with the restriction $F^{\prime}{ }_{\text {obs }}=0$ if

$$
\left(F_{\text {obs }(h k l)}\right)^{2}-\left(F_{\text {obs }(h \overline{k l})}\right)^{2}<0
$$

On the basis of these new structure factor values, $F^{\prime}{ }_{\text {obs }}$, full-matrix least-squares refinements were performed to the stage where no parameter shifts were obtained. The $R$-values obtained for the different sets of data are given in Fig. 1. From the figure we can see that the lowest $R$-value $(0.064)$

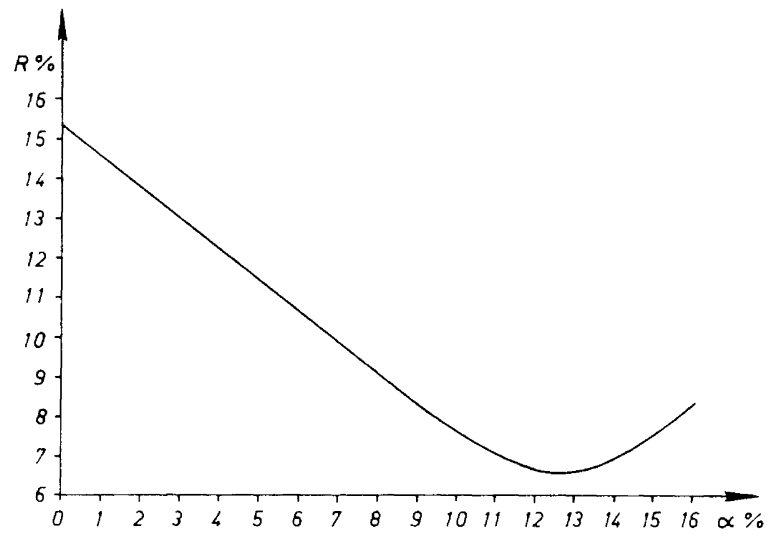

Fig. 1. $R$-values obtained for different sets of data based on different $\alpha$-values.

Table 3. Weight analysis obtained in the final cycle of the least-squares refinement of $\mathrm{Na}_{2} \mathrm{SO}_{3} . w=$ weighting factor, $\Delta=\| F^{\prime}{ }_{\text {obs }}|-| F_{\text {calc }}||$.

\begin{tabular}{|c|c|c|c|c|c|}
\hline $\begin{array}{c}\text { Interval } \\
F^{\prime} \text { obs }\end{array}$ & $\begin{array}{c}\text { Number of } \\
\text { independent } \\
\text { reflections }\end{array}$ & $-\frac{w \Delta^{2}}{\text { Interval }}$ & $\begin{array}{c}\text { Number of } \\
\text { sin } \theta\end{array}$ & $\begin{array}{c}w \Delta^{2} \\
\text { independent } \\
\text { reflections }\end{array}$ & \\
\hline & 11 & 0.67 & $0.00-0.46$ & 24 & 1.83 \\
$0.0-3.2$ & 13 & 0.99 & $0.46-0.58$ & 20 & 0.77 \\
$3.2-4.6$ & 13 & 0.68 & $0.58-0.67$ & 22 & 1.25 \\
$4.6-6.0$ & 13 & 2.16 & $0.67-0.74$ & 17 & 0.55 \\
$6.0-8.5$ & 14 & 1.86 & $0.74-0.79$ & 22 & 1.00 \\
$11.5-11.4$ & 14 & 0.99 & $0.79-0.84$ & 12 & 0.59 \\
$16.1-19.1$ & 14 & 1.05 & $0.84-0.89$ & 13 & 1.40 \\
$19.6-29.5$ & 14 & 0.55 & $0.89-0.93$ & 5 & 2.61 \\
$29.5-44.0$ & 14 & 0.62 & $0.93-0.97$ & 0 & 0 \\
$44.0-98.1$ & 15 & 0.41 & $0.97-1.00$ & 0 & 0 \\
\hline
\end{tabular}


is obtained for the set of data calculated with $\alpha=0.13$. This also gave the lowest standard deviations of the positional and thermal parameters.

Hughes' weighting function $w=h^{-2}\left|F_{\text {obs }}, \min \right|^{-2}$ for $\left|F_{\text {obs }}\right| \leq h\left|F_{\text {obs }}, \min \right|$ and $w=\left|F_{\text {obs }}\right|^{-2}$ for $\left|F_{\text {obs }}\right|>\left|F_{\text {obs }}, \min \right|$ with $h=4.0$ was used in the refinement.

The weight analysis obtained in the last cycle is given in Table 3 . The positional parameters and the temperature factors of all the atoms and their standard deviations are given in Table 4.

Table 4. The structure of $\mathrm{Na}_{2} \mathrm{SO}_{3}$.

Space group: $P \overline{3}$ (No. 147).

Unit-cell dimensions: $a=5.4587 \pm 5 \AA$

$c=6.1792 \pm 23 \AA$

Cell content: $2 \mathrm{Na}_{2} \mathrm{SO}_{3}$

Arrangement of atoms: $6 \mathrm{O}$ in $6(g): \pm(x, y, z): \pm(y, y-x, \bar{z}): \pm(y-x, \bar{x}, z)$

$1 \mathrm{Na}(1)$ in $1(a):(000): 1 \mathrm{Na}(2)$ in $1(b):\left(00 \frac{1}{2}\right)$;

$2 \mathrm{Na}(3)$ and $2 \mathrm{~S}$ in $2(d): \pm(1 / 3,2 / 3, z)$

\begin{tabular}{|c|c|c|c|c|}
\hline Atom & $x \pm \sigma(x)$ & $y \pm \sigma(y)$ & $z \pm \sigma(z)$ & $B \pm \sigma(B) \AA^{2}$ \\
\hline $\mathrm{Na}(1)$ & 0 & 0 & 0 & $2.82 \pm 0.15$ \\
\hline $\mathrm{Na}(2)$ & 0 & 0 & $1 / 2$ & $2.32 \pm 0.14$ \\
\hline $\mathrm{Na}(3)$ & $1 / 3$ & $2 / 3$ & $\begin{array}{c}0.6667 \\
(0.67)^{a}\end{array}$ & $3.44 \pm 0.15$ \\
\hline $\mathrm{S}$ & $1 / 3$ & $2 / 3$ & $0.1730 \pm 3$ & $2.06 \pm 0.11$ \\
\hline $\mathrm{O}$ & $\begin{array}{l}0.1313 \pm 10 \\
(0.14)^{a}\end{array}$ & $\begin{array}{c}0.3820 \pm 7 \\
(0.40)^{a}\end{array}$ & $\begin{array}{c}(0.17683 \pm 6 \\
(0.25)^{a}\end{array}$ & $\begin{array}{c}\text { Anisotropic } \\
(v . \text { infra })\end{array}$ \\
\hline
\end{tabular}

${ }^{a}$ Values according to Zachariasen and Buckley. ${ }^{6}$

The temperature factor for the oxygen atoms is of the form:

$$
T=\exp \left[B_{11} h^{2}+B_{22} k^{2}+B_{33} l^{2}+B_{12} h k+B_{13} h l+B_{23} k l\right]
$$

\begin{tabular}{|c|c|c|c|}
\hline Atom & $B_{11} \pm \sigma\left(B_{11}\right)$ & $B_{22} \pm \sigma\left(B_{22}\right)$ & $B_{33} \pm \sigma\left(B_{33}\right)$ \\
\hline 0 & $0.0332 \pm 24$ & $0.0246 \pm 23$ & $0.0269 \pm 15$ \\
& $B_{12} \pm \sigma\left(B_{12}\right)$ & $B_{13} \pm \sigma\left(B_{13}\right)$ & $B_{23} \pm \sigma\left(B_{23}\right)$ \\
0 & $0.0155 \pm 37$ & $0.0050 \pm 22$ & $0.0116 \pm 25$ \\
\hline
\end{tabular}

A three-dimensional difference synthesis calculated over the unique part of the unit cell at points spaced $0.2 \AA$ apart showed very small residual maxima or minima. The highest maximum was about $1 / 14$ of the height of the oxygen peaks in the $F^{\prime}$ obs synthesis.

Acta Chem. Scand. 23 (1969) No. 7 
Table 5. Interatomic distances $(\AA)$ and standard deviations ( $\pm \sigma$ in $\AA$ ) and the angle $\mathrm{O}-\mathrm{S}-\mathrm{O}$ within the sulphite group in $\mathrm{Na}_{2} \mathrm{SO}_{3}$.

$$
\begin{aligned}
& \mathrm{Na}(1)-6 \mathrm{O}=2.472 \pm 3 \\
& -2 \mathrm{Na}(2)=3.088 \pm 1 \\
& -6 \mathrm{~S}=3.327 \pm 1 \\
& \mathrm{Na}(2)-6 \mathrm{O}=2.327 \pm 3 \\
& -2 \mathrm{Na}(1)=3.088 \pm 1 \\
& -6 \mathrm{Na}(3)=3.315 \pm 1 \\
& \mathrm{Na}(3)-3 \mathrm{O}=2.447 \pm 4 \\
& -3 \mathrm{O}=2.823 \pm 4 \\
& -\mathrm{S} \quad=3.049 \pm 4 \\
& -3 \mathrm{O}=3.089 \pm 4 \\
& -\mathrm{S} \quad=3.126 \pm 4 \\
& -2 \mathrm{~S}=3.302 \pm 1 \\
& \mathrm{~S} \quad=3.305 \pm 1 \\
& 3 \mathrm{Na}(2)=3.315 \pm 1 \\
& \mathrm{~S}-3 \mathrm{O}=1.504 \pm 3^{a} \\
& -\mathrm{Na}(3)=3.049 \pm 4 \\
& -\mathrm{Na}(3)=3.126 \pm 4 \\
& -2 \mathrm{Na}(3)=3.302 \pm 1 \\
& -\mathrm{Na}(3)=3.305 \pm 1 \\
& -3 \mathrm{Na}(1)=3.327 \pm 1 \\
& \mathrm{O} \quad-\mathrm{S}=1.504 \pm 3^{a} \\
& -\mathrm{Na}(2)=2.327 \pm 3 \\
& -2 \mathrm{O}=2.397 \pm 6^{a} \\
& -\mathrm{Na}(3)=2.447 \pm 4 \\
& -\mathrm{Na}(1)=2.472 \pm 3 \\
& -\mathrm{Na}(3)=2.823 \pm 4 \\
& -\mathrm{Na}(3)=3.090 \pm 4 \\
& -2 \mathrm{O}=3.178 \pm 5 \\
& -2 \mathrm{O}=3.399 \pm 6 \\
& \mathrm{O}-\mathrm{S}-\mathrm{O}=105.69 \pm 17
\end{aligned}
$$

a Denote distances within the sulphite group.

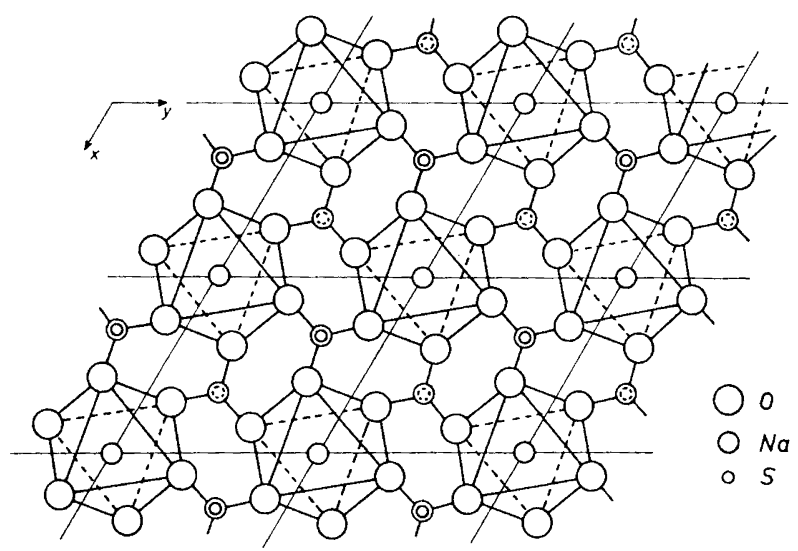

Fig. 2. Schematic drawing showing the structure of $\mathrm{Na}_{2} \mathrm{SO}_{3}$.

Acta Chem. Scand. 23 (1969) No. 7 
Table 6. Comparison between observed $\left(F_{\text {obs }}\right)$, twin corrected observed $\left(F^{\prime}\right.$ obs $)$ and calculated $\left(F_{\text {calc }}\right)$ structure factors. Reflections marked with an asterisk could not be twin corrected due to that corresponding $h k \bar{l}$ reflections were not observable.
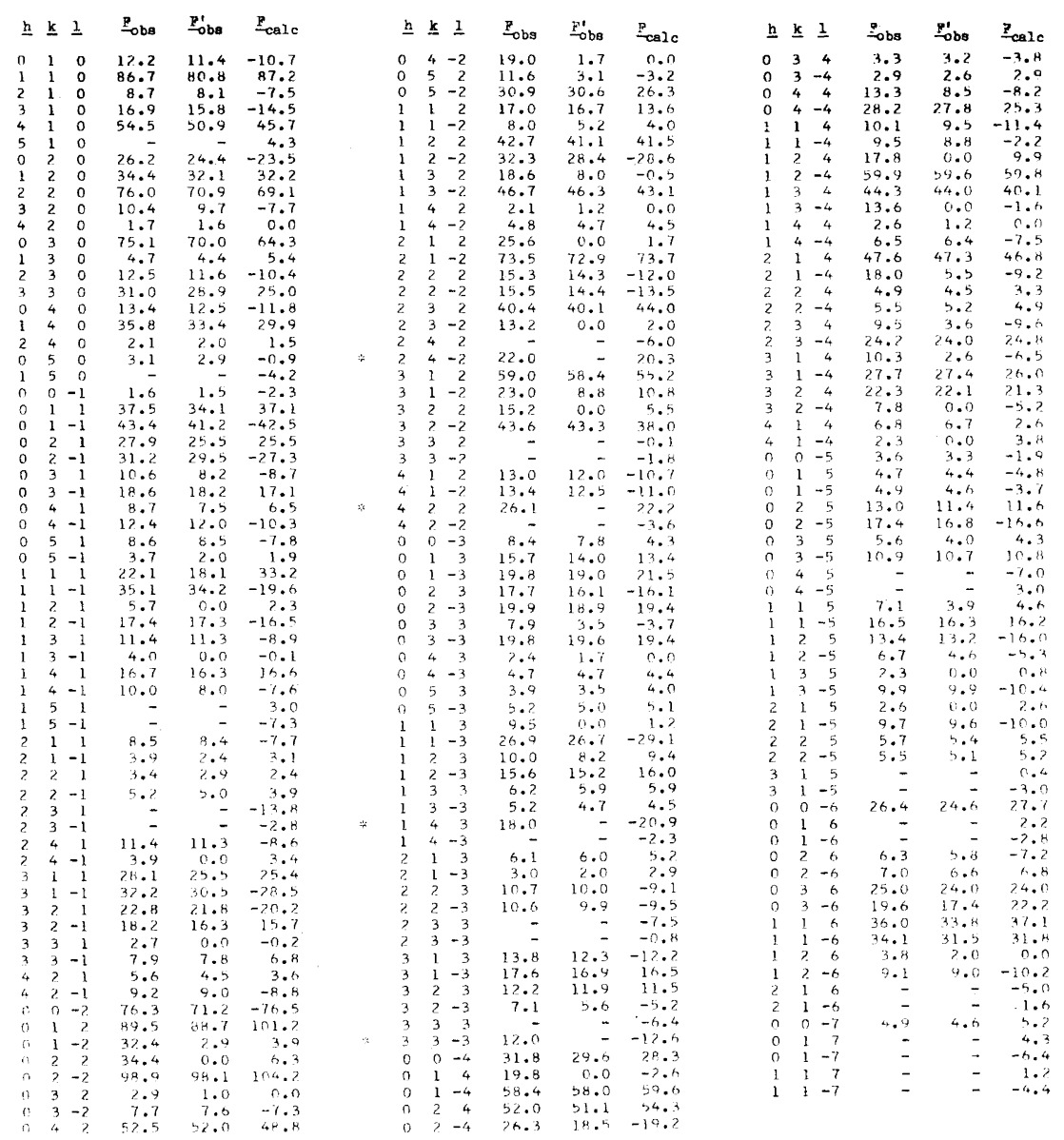

The calculated interatomic distances and their standard deviations are given in Table 5 .

A list of the observed, $F_{\text {obs }}$ and $F^{\prime}$ obs, and calculated structure factors is presented in Table 6 .

The refinement has shown that the structure of $\mathrm{Na}_{2} \mathrm{SO}_{3}$ as described by Zachariasen and Buckley is essentially correct. (A schematic drawing of the structure is shown in Fig. 2.) However, it has led to an appreciable change of the dimensions of the sulphite group. Thus the $\mathrm{S}-\mathrm{O}$ distance has been found to be $1.504 \pm 3 \AA$ and the angle $\mathrm{O}-\mathrm{S}-\mathrm{O} 105.69^{\circ} \pm 17$ as compared to the Acta Chem. Scand. 23 (1969) No. 7 
values 1.39 and 107.4 reported by the previous authors. The values obtained in this investigation are close to those found in several sulphites..$^{1-5}$ A further discussion of the structure of $\mathrm{Na}_{2} \mathrm{SO}_{3}$ as well as other sulphites will be given in a separate article.

Acknowledgements. The investigation has received financial support from the Swedish Natural Science Research Council and from The Tri-Centennial Fund of the Bank of Sweden. Permission for the use of the computers FACIT EDB, TRASK and CD 3600 was granted by the Computer Division of the National Swedish Rationalization Agency.

The authors wish to thank Professor Arne Magnéli for his encouraging interest and for all facilities placed at our disposal. We are also indebted to Dr. Sven Westman for correction of the English in this paper and to Mrs. Ingeborg Csöregh for valuable help with the intensity collection work at the manual diffractometer.

\section{REFERENCES}

1. Kierkegaard, P. and Nyberg, B. Acta Chem. Scand. 19 (1965) 2189.

2. Nyberg, B. and Kierkegaard, P. Acta Chem. Scand. 22 (1968) 581.

3. Larsson, L.O. Acta Chem. Scand. 23 (1969) 2261.

4. Baggio, S. and Becka, L. N. Acta Cryst. B 25 (1969) 1150.

5. Batelle, L. F. and Trueblood, K. N. Acta Cryst. 19 (1965) 531.

6. Zachariasen, W. H. and Buckley, H. E. Phys. Rev. 37 (1931) 1295.

7. Rocchiccioli, C. Compt. Rend. 244 (1957) 2704.

8. Swanson, H. E. and Fayat, R. K. N.B.S. Circular 539, vol. III (1954) 60.

9. Hambling, P. G. Acta Cryst. 6 (1953) 98.

Received February 6, 1969. 